\title{
BOOK REVIEW
}

Kenneth M Ehrenberg, The Functions of Law (Oxford: Oxford University Press, 2016), p. 217, $\$ 95.00$

At the start of The Functions of Law, Kenneth Ehrenberg suggests that many contemporary positivists downplay the significance of law's function(s) when offering an account of the nature of law. ${ }^{1}$ For example, some positivists argue that the distinctiveness of law resides, not in any function of law as such, but rather in the mode by which the law achieves whatever functions particular laws may have. ${ }^{2}$ It is, Ehrenberg suggests, anti-positivists such as Ronald Dworkin, along with natural law theorists, who tend to emphasise the importance of law's function in providing an account of the nature of law.

Ehrenberg sets out to challenge this state of affairs. His primary aim is to offer a positivist account of law that stresses the need to understand law's functions in order to better understand law's nature. Law, Ehrenberg tells us, is an institutionalised abstract artifact, and we better understand such artifacts by examining the functions they serve (p. 12). ${ }^{3}$ However, this is not to say that the key to distinguishing law from similar phenomena (such as organised religion and sporting clubs, or the rules thereof) lies in identifying law's functions. Ehrenberg suggests that some other social institutions may well serve the same functions as law. Thus, he offers a functionalist account of law that does not treat law as a "functional kind": he maintains that identifying law's functions is essential to providing an adequate explanation of law, but denies that doing so is sufficient to distinguish law from (say) religious orders or sporting clubs. It follows that an understanding of law's functions provides only part of an explanation of law - if we want an explanation of how the law differs from other, similar institutions, we need to look beyond law's functions - but

\footnotetext{
${ }^{1}$ Kenneth M. Ehrenberg, The Functions of Law (Oxford: Oxford University Press, 2016), pp. 1-2. (References to page numbers in parentheses are to this work.) Note that there is some tension between this claim and Ehrenberg's further claim (discussed below) that "the key arguments by exclusive positivists against inclusive positivists involve an emphasis on the idea that it is law's primary function to guide behaviour[]" (p. 94).

${ }^{2}$ See, e.g., Leslie Green, "Law as a Means", in Peter Cane (ed.), The Hart-Fuller Debate in the Twenty-First Century (Oxford: Hart Publishing, 2010), pp. 169-188. Ehrenberg responds to Green's argument at pp. 128139.

${ }^{3}$ Ehrenberg allows that not all artifacts have functions, but he claims that law does and that it should be understood in light of its functions (p. 31). He also appears to endorse John Gardner's suggestion that, strictly speaking, law is a genre or type of artifact; the actual artifacts are individual laws and legal systems (p. 12 note 23; referring to John Gardner, "The Legality of Law”, 17 Ratio Juris (2004) 168-181, p. 171).
} 
Ehrenberg believes that it is an important part, and I mention below some of his reasons for believing this.

So what are the functions of law? Ehrenberg says relatively little about this. In Chapter 8, he suggests some possibilities, such as coordinating behaviour, creating new reasons for those subject to the law and providing an institutional framework for generating and validating other institutions. However, one of the subsidiary aims of the book (which forms the focus of Chapter 6) is to establish a new research programme for jurisprudence. To obtain a better understanding of the functions of law, Ehrenberg suggests, we need to compile a catalogue of the various purposes of individual laws. This will require input from social scientists "and other legal studies researchers" (p. 138). Philosophers of law will then help to reduce these various purposes into a general account of law's functions, by identifying "patterns of generalizations that we could use to characterize law as a whole" (p. 138). However, while we should seek to identify commonalities between the functions of different laws, there is no reason to think that these are all reducible to a single function, given that a single artifact type is often used for multiple purposes. (Even if law has many different functions, Ehrenberg suggests, it can still be understood in light of those functions, in the same way that a Swiss army knife can: pp. 130-131.)

This gives rise to the book's main methodological prescription. The role of the legal philosopher, says Ehrenberg, is that of a "modest joiner". Not only should she generalise from the findings of social science as to the functions of specific laws, but she should also seek to reconcile the conclusions reached in this way with relevant theories from general philosophy. (As examples of the latter, Ehrenberg mentions “ordinary language philosophy, Quine's rejection of the analytic/synthetic distinction, Bratman's planning theory, and Searle's theory of institutional facts" (p. 140, footnotes omitted), while acknowledging that "[w]here the philosophical theory does not withstand the test of time, the jurisprudential theories that employ it are then rightfully critiqued and adapted[]" (p. 141).) Or, as he puts it in the Conclusion, "the jurisprudent takes successful philosophical theories from the wider literature and applies them to law, using empirical information to hone them[]" (p. 196). ${ }^{4}$

\footnotetext{
${ }^{4}$ It is unclear whether we are meant to start with the data about law obtained from social sciences or with relevant theories from general philosophy (compare pp. 133-134 with p. 147). However, our choice of starting point may not matter much for Ehrenberg's purposes.
} 
So far, I have focused on Ehrenberg's discussion of law's functions. However, it is important to Ehrenberg, not just that he vindicates a version of functionalism about law, but that this is a positivist (indeed, exclusive positivist) theory of law. Chapters 3-5 deftly combine these two goals, by providing a critique of other theories of law - Dworkin's interpretivism, natural law theory and inclusive legal positivism, respectively - that highlights their dependence on (what Ehrenberg regards as) mistaken views about law's function. (Chapter 5 also compares and contrasts Ehrenberg's preferred position with Scott Shapiro's planning theory of law.)

Ehrenberg further claims that understanding law as an institutionalised abstract artifact - and hence in terms of its functions - helps solve certain problems facing legal positivism. In Chapter 7, he addresses one such problem - namely, the concern that positivism struggles to account for law's normativity, since it claims that "law is merely a human creation" (p. 154). Ehrenberg discusses several aspects of this normativity problem, but perhaps his key claim is that paying attention to law's nature as an institutionalised artifact helps explain how law sometimes creates genuine (or "robust") reasons. His argument for this claim is not entirely clear. However, his starting point appears to be that artifacts like law differ from mere tools in that they are not only designed to achieve particular purposes or functions, but "are designed to be recognizable as the specific kind of tool that they are[]" (p. 176). For example, laws are meant to be recognised (and used) as laws, "by following the procedures for such recognition and use set by the system that validates them[]" (p. 175). In this way, laws come with certain "norms of treatment" attached. Since it is possible to create new artifact types, or variations on existing types, it must be possible to create new norms of treatment applicable to particular laws. Where the law possesses legitimate authority, Ehrenberg suggests, this involves the creation of new, robust reasons for the people subject to those laws (pp. 178-179).

There is much to admire about this book. Ehrenberg's functionalist theory of law is attractive in so far as it recognises that an account of law's functions can provide only part of an overall theory of the nature of law. This enables Ehrenberg to avoid making the strong claims about law's functions to which a functional kinds analysis of law is drawn. More generally, to the extent that positivists have offered functionalist theories of law, those theories have tended not to make use of contemporary work in general philosophy on artifacts and their functions. By contrast, throughout the book, but especially in Chapter 2, Ehrenberg 
draws on the broader philosophical literature on functions, artifacts and institutions in a way that will undoubtedly enrich jurisprudential discussion in future.

However, I am not sure that the best way to develop a functionalist account of law is to identify the purposes of individual laws and then to generalise from those findings. It seems likely that the purposes of individual laws are too varied to serve as a basis on which we can arrive at general, theoretically useful conclusions about the functions of law. In this respect, Ehrenberg's analogy with a Swiss army knife may be optimistic. ${ }^{5}$ A Swiss army knife has multiple functions, but those functions are still relatively limited in number. By contrast, the conjunction of the purposes of individual laws in a single legal system, let alone across legal systems, will be extremely long, and there may not be sufficient commonalities between the conjuncts to produce a manageable list of purposes for law as a whole.

Ehrenberg contends that even ascribing very abstract functions to law - such as coordinating or guiding behaviour - has proven to be theoretically useful (pp. 124, 195). This may be true, but it is not clear that we need to catalogue the purposes of individual laws in order to identify functions of this sort.

I will not pursue these concerns any further here. Instead, I want to focus on one of Ehrenberg's central claims about functional explanations - namely, that a viable explanation of a thing in terms of its function must allow for the possibility that the explanandum could fail to perform that function. This methodological precept provides the basis on which Ehrenberg rejects several competing theories of law, including Dworkin's interpretivism, Fuller's "procedural" natural law theory and strong "substantive" natural law theories. My focus will be on Ehrenberg's discussion of Dworkin, but some of the concerns I raise may also apply to his discussion of Fuller and strong natural law theory. ${ }^{6}$

\footnotetext{
${ }^{5}$ Ehrenberg borrows the analogy from Green: see Green, supra note 2, p. 184.

${ }^{6}$ I should mention that some of the claims Ehrenberg makes when presenting Dworkin's account of law are potentially misleading. For example, he repeatedly characterises Dworkin's theory as involving appeal to "shared values", or as equating the law with "moral and political principles that the community embraces" (pp. 55-56). While there is a sense in which Dworkin does claim that legal principles are the community's principles, this is because the community is committed to those principles (to preserve political integrity), not because those principles are consciously or subconsciously endorsed or embraced by members of the community.

I also think that Ehrenberg sometimes misunderstands the views of inclusive legal positivists, including Jules Coleman's distinction between "criteria of identification" and "criteria of validity" (discussed at pp. 63, 9394). Ehrenberg appears to understand this as a distinction between a set of criteria that metaphysically determines what counts as law and a set of criteria that metaphysically determines which laws are legally valid, such that (on Coleman's view) something can count as law and yet be legally invalid. The better way of
} 
In Law's Empire, says Ehrenberg, Dworkin ascribes to law the purpose or function of justifying the exercise of coercive power by the state. Moreover, on Dworkin's account, "interpretations of law that fail to justify the state's use or withholding of force from the perspective of critical morality are not valid legal interpretations" (p. 60). It follows, says Ehrenberg, that law cannot fail to fulfil its function of justifying state coercion, since anything that fails to justify state coercion does not count as law: for Dworkin, "[i]t is conceptually impossible for something to be valid law and to fail to justify the state's use of force[]" (p. 61). ${ }^{7}$ This means that Dworkin's attempt to offer a functional explanation of law fails to meet one of the success conditions for such an explanation. ${ }^{8}$

Why does Ehrenberg claim that, when explaining something in terms of its function, we must allow for the possibility that it could fail to perform that function? His main argument in support of this claim is set out in the following passage: ${ }^{9}$

If failure [to perform the purported function] is not a conceptual possibility, then the entity might have causal properties that are possibly or actually valuable to an agent, but we don't think that those properties would count as the entity's point or purpose. If it is conceptually impossible for that valued effect not to take place, we don't tend to think of the cause in terms of its utility to bring about that effect; we will tend instead to group cause and effect together as a single entity, event, or process, and not see one as useful for the sake of the other. (p. 29, footnote omitted)

understanding the distinction is as a distinction between the way in which we identify the content of the law and the way in which the content of the law is metaphysically determined.

Finally, Ehrenberg presupposes a very strong form of moral scepticism when discussing both Dworkin's right answer thesis and the debate between inclusive and exclusive legal positivists. Indeed, in the latter context, he attributes his scepticism to the theorists he discusses. He ascribes to exclusive legal positivists the view that "any true proposition of morality (if such exists) is beyond human epistemic access" (p. 91), in the course of explaining why they deny that moral considerations can operate as criteria of legal validity. Similarly, he attributes to inclusive legal positivists the claim that legal officials are free to make legal validity "depend on something of which it is beyond their ability to have concrete knowledge" (ibid). Few positivists on either side of this debate would embrace such a strong form of moral scepticism. (I do not take Ehrenberg simply to be rejecting moral cognitivism, or ascribing that view to other positivists. The claim is that, even if there are moral truths, we cannot know what they are. At p. 91, he treats the possibility that non-cognitivism is true as an additional reason why exclusive legal positivists deny that legal validity can depend on moral considerations.)

${ }^{7}$ This is true only if we use "law" in the interpretive sense. Dworkin allows that there is a sense in which Nazi Germany had law, even though it obviously failed to justify the state's use of force: Ronald Dworkin, Law's Empire (Oxford: Hart Publishing, 1998), pp. 101-104. I take Ehrenberg's response to be that, in the sense of "law" in which Nazi Germany had law, law does not have a function. It has a function only when we consider it in the interpretive sense and, in this sense, law cannot fail to achieve its function. (See p. 66 note 22.)

${ }^{8}$ Ehrenberg claims that the problem for Dworkin arises because of the right answer thesis (p. 60). This is, I think, a mistake. In Law's Empire, the right answer thesis follows from Dworkin's embrace of a particular interpretive theory - namely, law as integrity. By contrast, if Ehrenberg has identified a problem for Dworkin, that problem arises out of Dworkin's general account of legal interpretation.

${ }^{9}$ Ehrenberg also appeals to the intuition that $\mathrm{X}$ may be a token of a type that has a function even if $\mathrm{X}$ is unable to perform that function (p. 28). For example, a knife that is too blunt to cut is still a knife. 
It is not entirely clear what the argument is here. One interpretation of this passage is that, if something has a function, then it is a means to an end - i.e. the end of serving that function - and thinking of something in this way does not make sense if it necessarily achieves the end in question. In such a case, it is not possible to separate the thing from the end it achieves, and so it is not possible to distinguish between the thing and its function.

An alternative interpretation is that to have a purpose is to strive to achieve a goal, and this brings with it an attendant risk of failure (since we do not think of someone as striving to achieve a goal if they cannot help but succeed). ${ }^{10}$ If so, it must be possible that something that has a function could fail to achieve that function (at least if we treat "purpose" and "function" as interchangeable, as Ehrenberg does).

However, on either interpretation, the argument presupposes that success or failure is an all-or-nothing proposition. If, by contrast, we allow for the possibility that a thing will necessarily achieve a certain end to some degree or other, why can we not think of its function as being to achieve that end? It is distinguishable from the end in question because it may only imperfectly realise that end. And we can make sense of the thought that it strives towards achieving that end precisely because its degree of success is not pre-determined.

Arguably, this is how Dworkin viewed law in Law's Empire. As Ehrenberg notes, for Dworkin, only the best interpretation of a community's legal practices counts as correct; if there is a better interpretation, that interpretation is correct instead (p. 60). Nevertheless, the justification for the exercise of state coercion in one jurisdiction may be stronger than that in another, in two ways. First, the best interpretation of one community's legal practices may fit better with those practices than the best interpretation of another community's legal practices fits with its practices, and so may require regarding fewer past political decisions as mistaken. Second, the best interpretation of one community's legal practices may more closely resemble what would be morally required if not for the requirement of fit with past political decisions. It is therefore open to Dworkin to say that different legal systems can vary in their degree of success in justifying the exercise of state coercion.

\footnotetext{
${ }^{10}$ This may be one of the claims John Gardner makes in "Law's Aims in Law's Empire", in Scott Hershovitz (ed.), Exploring Law's Empire: The Jurisprudence of Ronald Dworkin (Oxford: Oxford University Press, 2006), pp. 207-224 at p. 216. Ehrenberg refers to this passage at pp. 29 note 44 and 60 note 11.
} 
In fact, Ehrenberg's critique of Dworkin may go awry for a more fundamental reason, since the better interpretation of Law's Empire may be that Dworkin does not ascribe a function to law. It is true that he talks about the need to identify - or at least the desirability of identifying - the purpose of our legal practices (which he claims is to justify the use of state coercion). ${ }^{11}$ Not unreasonably, Ehrenberg understands this as the claim that law has a certain function. Nevertheless, this may be a mistake. To say that a practice instantiates a certain value is different from saying that the practice has a certain function. Dworkin, one might think, makes a claim of the former sort - he argues that our legal practices instantiate a certain value (which, on his preferred version of interpretivism, is political integrity), which stems from the way they justify the exercise of state coercion.

Of course, we could say that the function of law is to instantiate that value. However, note how Ehrenberg characterises a function: “[a] thing's proper function is the characteristic ends that it yields (or is supposed to yield) which explain its presence, development, or selection[]" (p. 21, footnotes omitted). Law's instantiation of the value of integrity may not be best thought of as an end that it characteristically yields or is supposed to yield. ${ }^{12}$

(It is clearer that Dworkin does not offer a functionalist account of law in Justice for Hedgehogs. In that book, he claims that law is a branch of political morality. ${ }^{13}$ It would, I think, be a mistake to say that morality, or a branch thereof, is supposed to yield a certain outcome or end. That said, Ehrenberg does not discuss Justice for Hedgehogs, and might deny that his critique is meant to extend to the position Dworkin defends in that book.)

Even if Dworkin does offer a functionalist account in Law's Empire, he operates with a different conception of a function than does Ehrenberg. Ehrenberg's most general characterisation of a (proper) function is contained in the passage quoted above. However, he

\footnotetext{
${ }^{11}$ More precisely, Dworkin claims that the fundamental purpose of legal practice is to constrain the use of state power so that that power is used only in ways that are "licensed or required by individual rights and responsibilities flowing from past political decisions about when collective force is justified[]" (Dworkin, supra note 7, p. 93).

${ }^{12}$ Scott Shapiro offers a somewhat similar reason for denying that we can ascribe a functionalist account of law to Dworkin. He claims that to say that something has a function is to say that it is meant to secure a certain benefit. However, he continues, Dworkin's view is that state coercion secures the relevant benefits; the role of law is to justify that coercion. See Scott Shapiro, "On Hart's Way Out", 4 Legal Theory (1998) 469-507, p. 505 note 67 (and see pp. 64-65 for Ehrenberg's response).

${ }^{13}$ Ronald Dworkin, Justice for Hedgehogs (Cambridge, Mass.: Belknap Press, 2011), p. 405.
} 
also states that, when considering artifacts, "proper functions are generally understood to be design functions" (p. 24), and it is clear that he endorses this understanding. He characterises design functions as, generally speaking, the functions that the maker of the artifact intended it to have, or the "tasks that artifact inventors or designers envision for the artifact when fashioning it[]" (p. 24, footnote omitted). Yet Dworkin does not claim that law has the function of justifying state coercion - or of instantiating political integrity - because lawmakers intend that this is what the laws they make will do, or because they envisage this task for those laws.

Returning to the possibility that Dworkin does not offer a functionalist account of law at all, Ehrenberg anticipates that Dworkin might respond to his objection by abandoning the claim that law has a function. He argues that this response would undermine Dworkin's contention that law is an interpretive enterprise, since to interpret something is to see it in its best light and - says Ehrenberg - this "is to put it to a purposive use" (p. 63). However, for the same reasons that one might question whether Dworkin claims that law has a function, one might question whether we should think of Dworkinian interpretation in functionalist terms. This sort of interpretation seeks to understand a practice in light of the value that the practice instantiates, and - one might think - this is importantly different from understanding a practice in terms of the ends that the practice yields or is supposed to yield.

This may be part of a more general tendency on Ehrenberg's part to overstate the role that claims about law's functions play in jurisprudential debate. For example, in Chapter 5, he analyses the dispute between inclusive and exclusive legal positivists through the prism of the latter's claims about law's function. ${ }^{14}$ It is true that one aspect of this debate involves a disagreement about whether law has certain functions, and (if so) what the implications of this are. However, there is much more to the debate than this. While Ehrenberg may readily concede this point, focusing only on this aspect of the debate risks skewing things in favour of his preferred (exclusivist) position. ${ }^{15}$

None of this should lead us to overlook the substantial contribution made by The Functions of Law. In particular, by offering a novel version of a functionalist theory of law,

\footnotetext{
${ }^{14}$ As noted earlier, there is some tension between this approach and Ehrenberg's suggestion that many contemporary positivists downplay the significance of law's functions (see supra note 1).

${ }^{15}$ Though, as Ehrenberg acknowledges, some exclusive legal positivists deny that law (as such) has a function.
} 
and by introducing some of the recent philosophical work on functions (as well as artifacts and institutions) into the jurisprudential arena, Ehrenberg has significantly advanced some key debates in the philosophy of law. ${ }^{16}$

Dale Smith

Melbourne Law School

University of Melbourne

Carlton, Victoria 3053, Australia

Email:dale.smith@unimelb.edu.au

${ }^{16}$ I would like to thank Jan Mihal for helpful comments. 


\section{University Library}

\section{- M M I E E R VA A gateway to Melbourne's research publications}

Minerva Access is the Institutional Repository of The University of Melbourne

Author/s:

Smith, D

Title:

Book Review: Kenneth M. Ehrenberg, The Functions of Law

Date:

2017

Citation:

Smith, D. (2017). Book Review: Kenneth M. Ehrenberg, The Functions of Law. Law and Philosophy, 36 (2), pp.215-223. https://doi.org/10.1007/s10982-017-9294-4.

Persistent Link:

http://hdl.handle.net/11343/283234 